\title{
Stage-dependent decisions in a parasitic copepod practising environmental sex determination
}

\author{
Marilyn Michaud ${ }^{1,2, *}$, Frédéric Thomas ${ }^{1}$, Samia Becheikh ${ }^{2}$, André Raibaut ${ }^{2}$, \\ Jacqui A. Shykoff ${ }^{3}$, François Renaud ${ }^{1}$ \\ ${ }^{1}$ Centre de Recherche IRD de Montpellier, CEPM (UMR CNRS-IRD 9926), équipe 'Evolution des Systèmes Symbiotiques', \\ BP 5045, F-34032 Montpellier Cedex 1, France \\ ${ }^{2}$ Station Méditerranéenne de l'Environnement Littoral (SMEL), quai de la daurade, F-34200 Sète, Université \\ Montpellier II, France \\ ${ }^{3}$ Laboratoire d'Evolution et Systématique (URA 2154 CNRS), Université Paris-Sud, Bâtiment 362, F-91405 Orsay Cedex, France
}

\begin{abstract}
Evidence is accumulating about the way strategic decisions over an organism's lifetime may depend on its state and on external circumstances. In the parasitic copepod Pachypygus gibber sex is environmentally determined when the free-living infective stage (Copepodid 2) enters the host, the sea squirt Ciona intestinalis. Whereas in a rich trophic environment the Copepodid 2 develops into a typical male or into a typical female (both are unable to swim and must remain inside the host), in poor trophic conditions it develops into an alternative free-living stage able to swim and to leave the host, the atypical male. Thus this copepod life cycle is characterised by 2 fundamentally different freeliving stages. We conducted an experimental study to compare the priority decisions of the Copepodid 2 and of the atypical male in their habitat selection behaviour We showed that while Copepodid $2 \mathrm{~s}$ are mainly attracted by chernicals released by the host into the water, atypical males only respond to female and typical male cues. We discuss the adaptiveness on this behavioural difference in light of the ecological constraints met by the different stages of $P$. gibber.
\end{abstract}

KEY WORDS: Stage-dependent decisions - Choice behaviour - Environmental sex determination Copepod P Parasitism

\section{INTRODUCTION}

Understanding the ecology and the evolution of phenotypic plasticity (i.e. environmentally based changes in the phenotype) is one of the major challenges in evolutionary ecology (Stearns 1989, Spitze \& Salder 1996) In several taxa of vertebrates and invertebrates, sex determination depends on the environmental conditions experienced by individuals (Charnov \& Bull 1977, 1989, Charnov 1982). Environmental sex determination is particularly favoured by natural selection when the environment is patchy with respect to opportunities for breeding as a male or a female (Charnov \& Bull 1977 , Bull 1981). Evidence shows that environmental sex determination can occur at different life stages (see Karlin

•E-mail: marilyn.michaud@cepm.mpl.ird.fr
\& Lessard 1986) and can lead to several sexual phenotypes within the sexes (e.g. Becheikh et al. 1998). An important issue for evolutionary and behavioural ecologists is to understand how these developmental switches channel the decision-making processes in the context of habitat selection and reproductive strategies (Mangel \& Ludwig 1992, Carroll \& Corneli 1995, Gross 1996).

In the Crustacea the basis of sex determination is genetic, though an influence of various environmental and cytoplasmic factors has been shown in some species (Ginsburger-Vogel \& Charniaux-Cotton 1982, Korpelainen 1990). In copepods there is clear evidence of environmental sex determination in the free-living genera Cyclops, Macrocyclops, Eurytemora and Tigriopus and in the parasitic species Haemocera danae, Mytilicola intestinalis and Pachypygus gibber (Korpelainen 1990). 
On the Mediterranean French coasts, the copepod Pachypygus gibber (Thorell, 1859) specifically parasitises the sea squirt Ciona intestinalis (L.) and develops within the host (Hipeau-Jacquotte 1977. Heussner 1983, Becheikh et al. 1996). The parasite's life cycle is direct (i.e. only 1 host). Non-feeding larval stages, 6 nauplii and 2 copepodids, are free-living, and the second copepodid stage is the infective one (HipeauJacquotte 1978). As soon as the Copepodid 2 has entered a host, it develops to different adult forms according to conditions encountered within that host. Indeed, sex is environmentally determined, with at least 2 epigenetic proximal factors involved: resource availability and sexual partners already present in the host (Becheikh et al. 1998). Three adult phenotypes have been described in this species (Hipeau-Jacquotte 1978): 2 typical ones (male and female phenotypes whose development, reproduction, and death take place within the host) and 1 atypical dwarf male, able to exit from the host because of its ability to swim and to feed on plankton outside the host (Hipeau-Jacquotte $1980 \mathrm{a}, \mathrm{b})$. Typical development only occurs above a threshold resource quantity, whereas atypical development occurs in poor trophic conditions (Becheikh et al. 1998).

In this paper we conducted an experimental study under controlled conditions in order to analyse the decision priorities of the 2 fundamental free-living stages of Pachypygus gibber (the Copepodid 2 and the atypical male) in their habitat selection behaviour. In a state-dependent approach to life history, we can a priori predict that the best actions to perform in order to maximise fitness will be different between the two free-living stages. Because only adult forms of $P$. gibber can reproduce, we predict that Copepodid 2 should be first attracted by resource patches (i.e. hosts) in order to attain adulthood. As opposed to Copepodid $2 \mathrm{~s}$, atypical males are irreversibly engaged in a sexual phenotype ready to mate. Given that females are unevenly distributed among the host population (Becheikh et al. 1998), we predict that atypical males should respond more to female signal than to host signal. We also explore whether or not the decision priorities of Copepodid $2 s$ and atypical males are modified by the presence of typical males inside the host.

\section{MATERIALS AND METHODS}

Origin of biological samples. Hosts: Hosts used in the experiments were sea squirts Ciona intestinalis measuring at least $1 \mathrm{~cm}$ long. Uninfected $C$. intestinalis were obtained by in vitro fertilisation, and were reared in the laboratory. $C$. intestinalis already infected by a female of Pachypygus gibber could be collected from the Thau lagoon (Southern France, 432 $5^{\prime} \mathrm{N}, 3^{\circ} 35^{\prime} \mathrm{E}$ ) since adult female copepods were visible through the tunic of the host. Extracts of ground $C$. intestinalis were obtained by crushing uninfected individuals of 1.5 to $3 \mathrm{~cm}$ long in $5 \mathrm{ml}$ of filtered seawater.

Free-living stages: Fifty females of Pachypygus gibber taken from Ciona intestinalis from the Thau lagoon produced eggs (clutch size: mean $\pm \mathrm{SE}=841 \pm 55, \mathrm{n}=$ 31, M. Michaud unpubl. data) that were pooled and reared in filtered sea water in the laboratory until the Copepodid 2 stage. Atypical males were obtained by infecting very young uninfected $C$. intestinalis $(1,5$ to $3 \mathrm{~mm}$ long) with a random sample of these Copepodid 2s. Atypical males and Copepodid $2 \mathrm{~s}$ are respectively 0.76 to $1 \mathrm{~mm}$ long and 0.36 to $0.45 \mathrm{~mm}$ long.

Other parasitic stages: Fertilised adult females with eggs visible through their marsupium, unfertilised young females (late Copepodid 5 stage), and typical males of Pachypygus gibber were collected from Ciona intestinalis living in the Thau lagoon.

Procedure. Choice experiments were conducted in a Y-maze (Davenport 1950) using $0.5 \mathrm{~cm}$ tubing connecting three $8 \mathrm{~cm}$ diameter glass containers. The system was drip supplied with seawater to Compartments 1 and 2, and drained from Compartment 3. Water from the open sea, and not from the Thau lagoon, was used in order to prevent any bias caused by hosts living in the lagoon. To test the choice behaviour displayed by Copepodid 2 and atypical male stages, test individuals were initially placed in Compartment 3. Compartments 1 and 2 contained the targets of the choice experiment. Since these were either Ciona intestinalis or adult typical Pachypygus gibber, none of them are mobile. All experiments were conducted during a $4 \mathrm{~h}$ period, except for Experiment 2 (Table 1), which lasted only $20 \mathrm{~min}$. The distribution of the individuals originally placed in Compartment 3 was then recorded. Experiments were conducted at $18^{\circ} \mathrm{C}$ in the dark, since the Copepodid 2 is positively phototaxic (HipeauJacquotte 1977). To test for directional bias, an equal number of repetitions was carried out reversing the targets between Compartments 1 and 2 .

For each experiment involving the Copepodid 2,10 Copepodid 2s were initially placed in Compartment 3 , and 12 repetitions were carried out. For each experiment involving atypical males, 3 males were initially placed in Compartment 3 , and 10 repetitions were carried out. New individuals were used for each repetition.

Statistical analysis. The null hypothesis $\left(\mathrm{H}_{0}\right)$ could be a random distribution of individuals with equal probabilities of being in 1 of the 3 compartments. Due to the experimental set-up there is an obvious bias. Compartment 3 received all experimental individuals at the beginning of the experiment and water flushed from com- 
Table 1. Experimental choice behaviour of Copepodid 2. n1: total final number of Copepodid 25 in Compartment 1, n2: total final number of Copepodid $2 \mathrm{~s}$ in Compartment 2, $T$ : statistic of the Wilcoxon's signed-ranks test, $N$ : number of non-zero matched pair differences, $\mathrm{H}_{1}$ : alternative hypothesis of the test

\begin{tabular}{|c|c|c|c|c|c|c|c|c|}
\hline Expt & Compartment 1 & Compartment 2 & $\mathrm{n} 1$ & $\mathrm{n} 2$ & $T$ & $\mathrm{~N}$ & $\mathrm{H}_{1}$ & Significance \\
\hline 1 & Seawater & 1 uninfected Ciona & 23 & 71 & 78 & 12 & $1<2$ & $p \leq 0.001$ \\
\hline 2 & Seawater & Seawater previously occupied by Ciona ${ }^{4}$ & 27 & 62 & 66 & 11 & $1<2$ & $p \leq 0.001$ \\
\hline 3 & Seawater & Extract of ground Ciona & 24 & 65 & 78 & 12 & $1<2$ & $p \leq 0.001$ \\
\hline 4 & Seawater & 3 virgin females & 19 & 62 & 78 & 12 & $1 \neq 2$ & $p \leq 0.001$ \\
\hline 5 & Seawater & 3 fertilised females & 30 & 60 & 55 & 10 & $1 \neq 2$ & $p \leq 0.005$ \\
\hline 6 & 3 virgin females & 3 fertilised females & 41 & 38 & 22 & 8 & $1 \neq 2$ & $p>0.05$ \\
\hline 7 & Extract of ground Ciona & 3 virgin females & 70 & 22 & 78 & 12 & $1 \neq 2$ & $\mathrm{p} \leq 0.001$ \\
\hline 8 & 1 uninfected Ciona & 1 Ciona infected by a fertilised female & 43 & 43 & 18 & 8 & $1<2$ & $p>0.05$ \\
\hline 9 & Seawater & 3 typical males & 38 & 24 & 59 & 11 & $1>2$ & $p \leq 0.01$ \\
\hline 10 & Extract of ground Ciona & Extract of ground Ciona +3 typical males & 52 & 42 & 36 & 8 & $1 \neq 2$ & $p \leq 0.01$ \\
\hline 11 & Seawater & One uninfected Ciona +3 typical males & 27 & 68 & 78 & 12 & $1 \neq 2$ & $\mathrm{p} \leq 0.001$ \\
\hline
\end{tabular}

partment 1 and 2 directly to the third one. Therefore we considered in this analysis only individuals that moved from Compartment 3 , using the $\mathrm{H}_{0}$ of a random distribution of individuals between Compartment 1 and 2 . with a probability $1 / 2$ for each. Since we had a paired design (Compartment 1 versus Compartment 2), we used the non-parametric Wilcoxon's signed-ranks test for small samples with the $T$ statistic (Zar 1996). Differences of zero were ignored in the analysis. When $\mathrm{H}_{0}$ was tested against a well-defined directional prediction $\left(\mathrm{H}_{1}\right)$, a 1-tailed test was performed. When this was not the case, we performed 2-tailed tests. The threshold of significance value was set at 0.05 .

\section{RESULTS}

\section{Behavioural decisions made by Copepodid 2}

Results of choice behaviour experiments are listed in Table 1 . When given the choice between seawater and uninfected Ciona intestinalis, Copepodid 2 s displayed a clear preference for the compartment containing the host (Expt 1). This preference was still observed when the host compartment only contained seawater previously occupied by an uninfected $C$. intestinalis or by an extract of ground $C$. intestinalis (Expts 2 and 3).

When Copepodid 2 s could choose between seawater and females, they significantly preferred the compartment containing females, virgin or not (Expts 4 and 5). There was no differential preference between virgin females and fertilised ones (Expt 6). Copepodid 2 remained more attracted by an extract of ground Ciona intestinalis than by unfertilised females alone (Expt 7). No significant preference was observed when given the choice between an uninfected $C$. intestinalis and one harbouring a fertilised female (Expt 8).
When Copepodid 2 s had the choice between seawater and the typical males, they significantly avoid the compartment with typical males (Expt 9). They also preferred hosts without typical males over hosts with typical males (Expt 10). However, when offered a choice between hosts plus typical males versus seawater, they preferred the compartment containing hosts, despite the presence of the repulsive males (Expt 11).

Thus, although Copepodid $2 \mathrm{~s}$ are capable of responding to host and conspecific signals, priority is given to the host signal.

\section{Behavioural decisions made by atypical males}

Results of choice behaviour experiments are summarised in Table 2. In contrast to Copepodid 2s, atypical males were indifferent to the presence of uninfected Ciona intestinalis (Expt 12). Atypical males were attracted by both unfertilised and fertilised female copepods (Expts 13 and 14), although they displayed a significant preference for unfertilised ones (Expt 15). As opposed to Copepodid 2s, atypical males were more attracted by a host harbouring a fertilised female than by an uninfected host (Expt 16).

As Copepodid $2 \mathrm{~s}$, atypical males preferred the seawater compartment over that with typical males (Expt 17). When atypical males had the choice between females alone versus females with typical males, they preferred the females alone. This was true for both unfertilised (Expt 18) or fertilised (Expt 19) females. In addition, although unfertilised females were more attractive than fertilised ones (Expt 15 above), atypical males were more attracted by fertilised females on their own than by the more attractive unfertilised females when these were in the presence of typical repulsive males (Expt 20). 
Table 2. Experimental choice behaviour of atypical male. n1: total final number of atypical males in the Compartment 1, n2: total final number of atypical males in the Compartment 2. $T$ statistic of the Wilcoxon's signed-ranks test. N: number of non-zero matched pair differences, $\mathrm{H}_{1}$ : alternative hypothesis of the test

\begin{tabular}{|c|c|c|c|c|c|c|c|c|}
\hline Expt & Compartment 1 & Compartment 2 & n1 & $\mathrm{n} 2$ & $T$ & $\mathrm{~N}$ & $\mathrm{H}_{1}$ & Significance \\
\hline 12 & Seawater & 1 uninfected Ciona & 11 & 11 & 10.5 & 6 & $1 \neq 2$ & $p>0.05$ \\
\hline 13 & Seawater & 3 virgin females & 2 & 26 & 55 & 10 & $1<2$ & $\mathrm{p} \leq 0.0025$ \\
\hline 14 & Seawater & 3 fertilised females & 0 & 30 & 55 & 10 & $1<2$ & $p \leq 0.0025$ \\
\hline 15 & 3 virgin females & 3 fertilised females & 22 & 8 & 48 & 10 & $1 \neq 2$ & $\mathrm{p} \leq 0.05$ \\
\hline 16 & 1 uninfected Ciona & 1 Ciona infected by an fertilised female & 1 & 24 & 55 & 10 & $1<2$ & $\mathrm{p} \leq 0.0025$ \\
\hline 17 & Seawater & 3 typical males & 15 & 6 & 28 & 7 & $1>2$ & $\mathrm{p} \leq 0.01$ \\
\hline 18 & 3 virgin females & 3 virgin females +3 typical males & 24 & 5 & 45 & 9 & $1>2$ & $p \leq 0.0025$ \\
\hline 19 & 3 fertilised females & 3 fertilised females +3 typical males & 25 & 4 & 45 & 9 & $1>2$ & $p \leq 0.0025$ \\
\hline 20 & 3 fertilised females & 3 virgin females +3 typical males & 26 & 3 & 55 & 10 & $1 \neq 2$ & $p \leq 0.005$ \\
\hline
\end{tabular}

Thus, in contrast to Copepodid 2s, atypical males do not respond to host signal but display higher level of responses to female and typical male signals.

\section{DISCUSSION}

For parasites, the host supplies resources in the form of space, food and for gonochoric species, a 'rendezvous' site for finding mates. If hosts and parasites inside hosts are not uniformly distributed, strong selective pressures will operate on free-living parasite stages to maximise finding an appropriate host (Poulin 1998). A flexible developmental program may afford parasites the opportunity to make the best of difficult situations provided that the optimal decision changes over time

The Copepodid 2 of Pachypygus gibber is more attracted by the host than by females whereas the opposite pattern is observed for atypical males. These results first support the idea that behavioural decisions in $P$. gibber depend both on its state and on external circumstances. In a state-based approach to life-histories, the contrasted decision priorities of the 2 free-living stages can be viewed as adaptive adjustments to maximise fitness. Because only adult forms of $P$. gibber reproduce, a first task for Copepodid 2 is to locate in the environment a host in order to reach adulthood. According to our results (Expts 2 and 3), this attraction is due to chemicals released by the host into the water. In the absence of host signal (Expts 4 and 5), Copepodid 2 s were apparently able to respond to female signal. Female presence may correspond to 3 types of information: (1) presence of a Ciona intestinalis, (2) a rich habitat, and (3) a potential mate. However, this attraction was not observed. when females were inside the host (Expt 8), suggesting that host signal has priority over female signal. In natural conditions, the crucial need to find a host before energy reserves are depleted (the Copepodid 2 does not feed) could explain why priority is given to host signal for this infective larval stage. In addition, it can be of no importance for Copepodid 2 to prefer hosts harbouring a female if the proportion of rich habitats is high (i.e. female development is expected, Becheikh et al. 1998) and if Copepodid 2 achieves similar fitness by developing into a female rather than into a male when a female is already present (see Becheikh et al. 1998). Further information on the reproductive success of the different sexual phenotypes and on the proportion of rich and poor habitats in natural conditions are necessary to address this point.

Although females live inside the host, atypical males did not respond to host signal by itself. This major difference between Copepodid 2 s and atypical males can arise for several reasons. It is possible that gradients of host chemicals are used by Pachypygus gibber mainly to locate patch of hosts at large scale. Given the aggregated distribution of Ciona intestinalis in the environment (Michaud unpubl. obs.), Copepodid 2s differentiating into atypical males are likely to have already reached a patch of hosts. Since chemosensory organs involved in the detection of host chemicals would be useless and probably costly to maintain, selection should favour their loss when Copepodid 2 s differentiate into atypical males. In addition, because females are unevenly distributed among hosts (Becheikh et al. 1996), attraction to female cues per se is likely to be the strategy favoured by selection. Results previously obtained on Copepodid 2 (Expts 5 and 8 ) could suggest that female detection is indeed better when individuals do not simultaneously respond to host chemicals. Atypical males appeared also able to discriminate between virgin and fertilised females. The adaptive value of such a discrimination seems here obvious since atypical males preferring virgin females can immediately ensure paternity without having to wait for the production of a new batch of eggs by the female. Further investigations are needed to understand the proximal factors allowing atypical males to discriminate between fertilised and unfertilised females.

Although Copepodid $2 \mathrm{~s}$ and atypical males are both repulsed by typical males, their main decision priori- 
ties with regard to host and female signals are not changed. Attempts to avoid typical males thus only occurs when the main exigencies of the 2 free-living stages can be realised in several hosts. For a Copepodid 2, the presence of typical males correspond to several situations unlikely to maximise its fitness. Indeed, according to Becheikh et al. (1998), development into typical males occurs when the environment is not rich enough to produce a female or when a female is already present in the host. Provided Copepodid 2 still has time before its energy reserves are depleted, finding another host may be a better option than producing a female in a non-optimal environment or being in competition with another male for the access to the female. Further studies are needed to determine whether or not the behavioural decision of a Copepodid 2 in such a case is influenced by its age and by its previous searching experience (e.g. Real 1990). For atypical males that are irreversibly engaged in this sexual phenotype, the presence of typical males is always equivalent to sexual competitors. Given their tiny size, atypical males are likely to be at a selective disadvantage with typical males in the competition for the access to females. The fact that atypical males preferred fertilised females alone over virgin females together with typical males suggests that this disadvantage could be strong.

In conclusion, these findings first support the idea that environmental conditions influence the developmental and the behavioural programs in Pachypygus gibber. Habitat selection behaviour in this copepod can be viewed as a hierarchical and state-dependent process, in which individuals first choose a general place in which to live and then make subsequent decisions about the use of different patches responding specifically to other stimuli.

Acknowledgements. We thank Dr M. Raymond (University of Montpellier II-CNRS, France) and Dr T. de Meeüs (CNRSIRD, France) for helpful comments, and M. Cantou and L. Libicz (SMEL, University of Montpellier II, Sète, France) for their essential contribution in sampling sea squirts in the Thau lagoon. M.M. was supported by a grant from M.E.N.E.S.R.

\section{LITERATURE CITED}

Becheikh S, Thomas F, Raibaut A, Renaud F (1996) Some aspects of the ecology of Pachypygus gibber (Copepoda), an associated organism of Ciona intestinalis (Urochordata). Parasite 3:247-252

Becheikh S, Michaud M, Thomas F, Raibaut A, Renaud F (1998) Roles of resource and partner availability in sex

Editorial responsibility: Otto Kinne (Editor),

Oldendorf/Luhe, Germany determination in a parasitic copepod. Proc R Soc Lond B 265:1153-1156

Bull JJ (1981) Sex ratio evolution when fitness varies. Heredity $46: 9-26$

Carroll SP, Corneli PS (1995) Divergence in male mating tactics between two populations of the soapberry bug : II. Genetic change and the evolution of a plastic reaction norm in a variable social environment. Behav Ecol 6: 46-56

Charnov EL (1982) The theory of sex allocation. Princeton University Press, Princeton, NJ

Charnov EL, Bull JJ (1977) When is sex environmentally determined? Nature 266:828-830

Charnov EL, Bull JJ (1989) The primary sex ratio under environmental sex determination. J Theor Biol 139:431-436

Davenport D (1950) Studies in the physiology of commensalism. I. The polynoid genus Arctonoë. Biol Bull 98:81-93

Ginsburger-Vogel T, Charniaux-Cotton $H$ (1982) Sex determination. In: Bliss DE (ed) The biology of Crustacea (Vol 2). Academic Press, London, p 257-281

Gross MR (1996) Alternative reproductive strategies and tactics: diversity within sexes. TREE 11:92-98

Heussner S (1983) Parasitisme de Pachypygus gibber (Thorell, 1859), copépode ascidicole à deux formes mâles. Dynamique saisonnière de l'association avec l'hôte Ciona intestinalis (L.). Hypothèses sur le déterminisme sexuel du parasite. Thèse de Doctorat, University of Aix-Marseille II

Hipeau-Jacquotte R (1977) Ethologie du stade infestant du copépode ascidicole Notodelphyidae Pachypygus gibber. Réactions à la lumière au cours de la vie larvaire pélagique. Mar Biol 44:57-63

Hipeau-Jacquotte R (1978) Développement post-embryonnaire du copépode ascidicole Notodelphyidae Pachypygus gibber (Thorell, 1859). Crustaceana 34:155-194

Hipeau-Jacquotte R (1980a) Le développement atypique du copépode ascidicole Notodelphyidae Pachypygus gibber (Thorell, 1859). Arch Zool Exp Gén 121:29-47

Hipeau-Jacquotte R (1980b) La forme mâle atypique du copépode ascidicole Notodelphyidae Pachypygus gibber (Thorell, 1859): description et synonymie avec Agnathaner minutus Canu, 1891). Bull Mus Natl Hist Nat Paris $4: 455-470$

Karlin S, Lessard S (1986) Theoretical studies on sex ratio evolution. Princeton University Press, Princeton, NJ

Korpelainen H (1990) Sex ratios and conditions required for environmental sex determination in animals. Biol Rev 65: $147-184$

Mangel M, Ludwig D (1992) Definition and evaluation of the fitness of behavioural and developmental programs. Annu Rev Ecol Syst 23:507-536

Poulin R (1998) Evolutionary ecology of parasites. Chapman \& Hall, London

Real L (1990) Search theory and mate choice. I. Models of single-sex discrimination. Am Nat 136:376-405

Spitze K, Salder TD (1996) Evolution of a generalist genotype: multivariate analysis of the adaptiveness of phenotypic plasticity. Am Nat 148:108-123

Stearns SC (1989) The evolutionary significance of phenotypic plasticity. BioScience 39:436-445

Zar JH (1996) Biostatistical analysis (3rd edn). Prentice Hall Upper Saddle River, NJ, p 167-169

Submitted: January 13, 1999; Accepted: April 9, 1999

Proofs received from author(s): July 26, 1999 